\title{
Introducing the Special Issue: Bilingualism in the Hispanic and Lusophone World
}

\author{
Anel Brandl ${ }^{1}$, Carolina González ${ }^{1, *}$, Michael Leeser ${ }^{1}$, Antje Muntendam ${ }^{1}$, \\ M. Carmen Parafita Couto ${ }^{2}$ (D) and Lara Reglero ${ }^{1}$ \\ 1 Department of Modern Languages and Linguistics, Florida State University, 600 W. College Avenue, \\ 32306 Tallahassee, FL, USA; abrandl@fsu.edu (A.B.); amuntendam@fsu.edu (A.M.); mleeser@fsu.edu (M.L.); \\ lreglero@fsu.edu (L.R.) \\ 2 Center for Linguistics, Leiden University Room 1.02b, Van Wijkplaats 3, 2311 BX Leiden, The Netherlands; \\ m.parafita.couto@hum.leidenuniv.nl \\ * Correspondence: cgonzalez3@fsu.edu; Tel.: +1-850-644-817
}

Academic Editors: Usha Lakshmanan and Osmer Balam

Received: 13 December 2017; Accepted: 22 December 2017; Published: 22 December 2017

This Special Issue of Languages includes nine selected and peer-reviewed papers from the second meeting of Bilingualism in the Hispanic and Lusophone World (BHL), an international conference that took place at Florida State University, in Tallahassee, Florida, USA, in January 2017. Research on bilinguals and bilingual (and multilingual) communities in the Iberian Peninsula, Latin America, and the United States has occupied the interest of language researchers from several disciplines for some time, and recent years have witnessed an impressive number of peer-reviewed publications. For example, a search in the Linguistics and Language Behavior Abstracts database from 2011-2016 yields over 1000 citations of studies investigating some aspect of bilingualism in the Hispanic and Lusophone world (http:/ / www.proquest.com/products-services/llba-set-c.html). Given the strong interest and wide array of topics explored in this field, Antje Muntendam (Florida State University) and M. Carmen Parafita Couto (Leiden University) initiated BHL, and the first meeting took place in Leiden, in 2015. The goal of the biannual BHL is to bring together scholars working on bilingualism in the Hispanic and Lusophone world from various disciplines such as theoretical linguistics, sociolinguistics, language contact, second language acquisition, heritage languages, communication, education, and psycholinguistics. The conference, in addition to the articles in this special issue, understands "bilingualism" in a broad and inclusive sense; that is, the capacity to function in more than one language. The advantage of this perspective is that it highlights the complex nature of bilingualism and allows researchers to consider factors such as the level of proficiency in each language, age of acquisition (early versus late bilingualism), order of acquisition (simultaneous versus sequential bilingualism), and context of acquisition (naturalistic versus instructed), as well as the fact that some speakers possess knowledge of additional languages (multilinguals). Indeed, in the 2017 conference, researchers from the United States, Canada, and Europe presented state-of-the-art work on bilingualism in children and adults from a wide variety of approaches and multilingual contexts in nearly 50 presentations and poster sessions. Furthermore, the conference featured plenary sessions by Teresa Bajo (University of Granada), Ana Carvalho (University of Arizona), Luis López (University of Illinois at Chicago), Virginia Mueller Gathercole (Florida International University), Armin Schwegler (University of California Irvine), and Gretchen Sunderman (Florida State University).

The nine articles selected for this Special Issue reflect the diversity of perspectives and research interests of BHL 2017. They cover a range of issues (age, code-switching, linguistic environment, language competition, language transfer, literacy) and employ a wide variety of tasks (visual world, sentence-picture matching, spontaneous oral production, sociolinguistic questionnaires, oral narration, self-paced reading, word naming). They also focus on various domains of linguistic knowledge 
(phonetics/phonology, morphology, lexicon, syntax) of children and adults from a number of language groupings (European Portuguese-German, Spanish-Basque, Spanish-English, Spanish-Galician, and Spanish-English-Brazilian Portuguese).

Three of the articles in this special issue focus on phonetics/phonology. In their article, Dean and Valdés Kroff investigate the effects of competing orthographic-phonological mappings in Spanish-English bilingual language processing [Dean and Valdés Kroff]. Using a visual word paradigm in an eye-tracking context, they tested a Spanish-dominant group and an English-dominant group in two different types of competing orthographic-phonological mappings: (i) 'b-v' (banco-vaca 'bench-cow'), and (ii) ' $\mathrm{j}$-h' (jabón-hacha 'soap-axe'). As hypothesized, the results show that the Spanish-dominant group exhibits competition effects in the ' $b-v^{\prime}$ trials. Such competition effects are not observed in the English-dominant group, which is attributed to the fact that ' $b$ ' and ' $v$ ' correspond to different phonemes in English. Contrary to expectation, competition effects are not attested for the English-dominant group in the ' $\mathrm{j}$-h' trials, despite orthographic differences in the representation of the phoneme /h/. Furthermore, the Spanish-dominant group exhibited effects of competition, which was unexpected given that the task was in Spanish, their native language. The authors suggest that the orthographic mappings of English, their L2, and the language of current immersion are giving rise to the relevant competition effects.

The article by Elias, McKinnon and Milla Muñoz examines vowel duration and quality in Spanish vowels in heritage speakers from the U.S. Midwest [Elias et al.]. The main questions explored are whether lexical stress and/or English-Spanish code-switching have an impact on Spanish vowel quality and duration, and whether vowel duration and quality are affected more the closer the vowels are to the code-switch site. The authors analyzed English to Spanish intra-sentential code-switches from eleven heritage speakers of Spanish; Praat was utilized to extract F(ormant)1 and F(ormant)2 values, as well as vowel duration. The results show that vowels are significantly shorter and more centralized in unstressed positions than in stressed ones, as well as in code-switched contexts compared to monolingual ones. There was no effect of distance from the code-switching site on any of the dependent variables. This article contributes to our understanding of both the phonological effects of code-switching and the phonological system of heritage speakers of Spanish.

The article by Muxika-Loitzate explores the phonemic status of three coronal sibilants in Biscayan Basque: apico-alveolar, lamino-alveolar, and prepalatal [Muxika-Loitzate]. Although these sibilants are merging in many varieties of Basque, the impact of Spanish-Basque bilingualism in this merging has not been explored previously. The author explores the extent to which merging occurs in Biscayan Basque, and the specific result of this merger, taking into consideration the degree of bilingualism, word position, and stress. Center of gravity was measured as a correlate of place of articulation for the sibilants on four Basque-dominant and six Spanish-dominant participants. The results show that merging is more advanced in Spanish-dominant speakers and less so in Basque-dominant speakers, who show a significant difference between the center of gravity corresponding to lamino-alveolar and prepalatal sibilants. In addition, the sibilant produced by Spanish-dominant speakers is significantly less fronted than the lamino-alveolar sibilant realized by Basque-dominant speakers. Muxika-Loitzate's article contributes to our understanding of the effect of bilingualism on the phonological system, and to the analysis of the phonetic characteristics of sibilants in Basque.

The article by Anderson studies morphology in another contact variety in the Iberian Peninsula, in particular Galician Spanish. In her article, Anderson examines transfer from Galician by investigating the acceptability of $-r a$ and $-s e$ forms for the imperfect subjunctive in Galician Spanish [Anderson]. The author hypothesizes that the -se form may be the preferred choice, given that Galician also uses the $-s e$ ending in the imperfect subjunctive ( $-r a$ is employed in the simple pluperfect indicative). The author explores the effects of age, sex, primary language, and possibility of the event using an online acceptability rating task. The stimuli consisted of conditional statements with different combinations of verb forms in protasis and apodosis. During the task, 29 speakers of Galician Spanish were asked to rate a series of statements and to correct statements that they rejected as 
incorrect. The results from the acceptability task show that neither social nor linguistic factors affect the acceptance of the $-r a$ and $-s e$ forms in Galician Spanish. That is, both possibilities are accepted at similar rates, indicating no pragmatic differences between $-r a$ and $-s e$. However, the production results point to individual differences, indicating an asymmetry between acceptability and production. Anderson's results do not support the hypothesis that the influence of the Galician language facilitates maintenance of the - se form.

Whereas the previously discussed articles study bilingual adults, four of the five remaining articles focus on bilingual children, and in particular, on the lexicon and morpho-syntax. In their article, Correia and Flores investigate the lexical development of European Portuguese by 6- to 11-year-old European Portuguese-German bilingual children (heritage speakers of European Portuguese) [Correia and Flores]. Specifically, the article examines: (1) whether bilingual children differ from monolingual children regarding vocabulary size and the distribution of nouns, verbs, and adjectives; and (2) which input factors have an effect on the lexical development of the bilingual children. The data come from a sociolinguistic questionnaire and an oral production task with 23 bilingual and 21 monolingual children. The bilingual children produced significantly fewer lexical items than the monolingual children. In particular, they produced fewer nouns and verbs. Interestingly, the two groups did not differ in lexical distribution: both groups produced more nouns than verbs, and more verbs than adjectives. Regarding input factors, children who received more exposure to European Portuguese at home and who interacted more in European Portuguese at home produced more lexical items. Moreover, the number of European Portuguese parents was positively correlated with lexical development. The authors conclude that the input and interaction in the home environment and with parents play an essential role in the lexical development of these children.

The article by Wood, Bustamante, Fitton, Brown and Petscher describes a preliminary study to test the practicability of a rapid automatic naming (RAN) task for young Spanish-English speaking dual language learners (DLLs) [Wood et al.]. Using the double deficit hypothesis as the framework, the authors explore the relationship between children's performance on RAN and other standardized assessments of reading readiness, nonverbal intelligence, receptive vocabulary, and sentence imitation. A total of 275 Spanish-English bilingual children enrolled in kindergarten and first grade completed an RAN task and four different assessments of language and early literacy: (i) the Woodcock Reading Mastery Tests, (ii) the Primary Test of Nonverbal Intelligence, (iii) the Peabody Picture Vocabulary Test, and (iv) the Bilingual English and Spanish Assessment. The results indicate that the RAN task was viable for $74 \%(n=203)$ of the learners. The authors also found positive correlations between RAN and scores in receptive vocabulary, letter identification, and non-verbal intelligence. No significant relationship was found with phonological awareness, which according to the authors, supports the double deficit hypothesis. The authors suggest that RAN is a feasible and useful measure for young Spanish-English speaking DLLs.

The study by Rodríguez, Bustamante, Wood and Sunderman expands the body of research that examines the production patterns of young heritage speakers in the L1 and the L2, and the interrelationship between the two languages in language development [Rodriguez et al.]. Using the morphosyntax subtest of the Bilingual English-Spanish Assessment, the authors elicited English and Spanish oral production from 45 children (35 in kindergarten and 20 in first grade, all heritage speakers of Spanish). They focused on verb morphology, in particular the subjunctive, the progressive, and the passive voice. Overall, their findings indicate that children produce more target structures in L1 Spanish, supporting the view that sequential bilingualism and continuous exposure to the heritage language may help heritage speakers to maintain some L1 structures. The results also suggest that instruction in the L2 does not necessarily involve L1 loss when the heritage speakers begin instruction in the majority language.

The article by Morales-Reyes and Arechabaleta-Regulez explores the effects of age and linguistic environment on L1 Spanish-L2 English children's interpretation of bare plural and definite plural noun phrases (NPs) in English (e.g., lions versus the lions) [Morales-Reyes and Arechabaleta-Regulez]. 
Although both English and Spanish permit bare and definite plural NPs, the two languages differ in terms of the mapping of these two plural NP types onto either specific or generic semantic interpretations (e.g., 'lions in general' versus 'a subset of lions'). Therefore, their study investigates whether L1 Spanish-L2 English children would show evidence of L1 transfer in their interpretation of bare and definite plural NPs. The participants included younger children (4- to 7-year-olds) and older children (8- to 11-year-olds) from Puerto Rico, who completed a computerized experiment in which they heard yes-no questions containing the two types of plural NPs, and responded based on pictures presented on the computer screen. In addition to age, the participants were grouped according to whether their linguistic environment was mostly Spanish, mostly English, or balanced between the two languages. The results suggest that neither age nor linguistic environment plays a significant role in NP interpretation. Instead, all of the L2 learners, as well as L1 English children, incorrectly extended a generic interpretation to definite NPs, although this overextension was significantly greater among the L2 learners, suggesting an L1 Spanish influence.

Finally, the last article discussed here focuses on syntax in L3 learners [Parma]. Parma's article investigates competing proposals regarding cross-linguistic transfer in the beginning stages of L3 acquisition. That is, can the syntax of all previously acquired languages potentially transfer to the new language? Or does the most recently acquired language (L2) primarily serve as the source of transfer to the L3? Or does typology/structural similarity between the L3 and one of the previously acquired languages mediate transfer? To address these questions, two groups of beginning-level L3 Brazilian Portuguese learners (L1 English-L2 Spanish and L1 Spanish-L2 English) and one group of L1 Brazilian Portuguese speakers performed a self-paced reading task and an oral story retelling task, both of which focused on object clitics in Brazilian Portuguese. The analysis of reading times in the self-paced reading task revealed no clear evidence of transfer from English or Spanish for either of the L3 BP groups. For the oral story-retelling task, however, the results suggest some negative transfer from Spanish. The L3 learners did not produce enough clitics to yield statistically significant findings, but an examination of the production errors revealed some influence of Spanish syntax for structures involving null objects and clitic placement, regardless of whether Spanish was the L1 or L2. Although cautious in his interpretation of the findings, Parma makes a convincing argument for the role of typological similarity to account for his results.

Together, the articles in this special issue contribute to our understanding of central issues (e.g., age, language dominance, linguistic environment, acquisition order, typology) in bilingualism research. Although we hope future special issues coming out of BHL will include more research on multilingualism and multilingual communities, we believe this collection reflects the variety of issues, methodologies, and linguistic domains of current research on bilinguals in the Hispanic and Lusophone world. We are grateful to have the opportunity to present this diversity in this Special Issue of Languages.

Acknowledgments: The 2017 BHL conference would not have been possible without the financial assistance and support of many individuals and institutions. We would like to thank the College of Arts and Sciences at Florida State University, as well as the Office of Research, the Winthrop-King Institute for Contemporary French and Francophone Studies, the Graduate School, the W. Russell and Eugenia Morcom Chair of Psychology and Education, the Department of Modern Languages and Linguistics, and the School of Communication. Finally, we thank the hard work of the graduate student volunteers who enthusiastically contributed their time and effort before, during, and after the conference. Regarding the preparation of this special issue, we would like to thank the anonymous external reviewers of the articles, as well as the Editors of the Languages journal.

Author Contributions: All the authors contributed equally to this Editorial.

Conflicts of Interest: The authors declare no conflict of interest.

\section{References}

1. Dean, C.A., and J.R. Valdés Kroff. 2017. Cross-Linguistic Orthographic Effects in Late Spanish-English Bilinguals. Languages 2: 24. [CrossRef] 
2. Elias, V., S. McKinnon, and Á. Milla Muñoz. 2017. The Effects of Code-Switching and Lexical Stress on Spanish Heritage Speaker Vowel Quality and Duration. Languages 2: 29. [CrossRef]

3. Muxika-Loitzate, O. 2017. Sibilant Merger in the Variety of Basque Spoken in Amorebieta-Etxano. Languages 2: 25. [CrossRef]

4. Anderson, A.M. 2017. On the Acceptability and Use of - ra and -se in Conditional Phrases in Galician Spanish. Languages 2: 21. [CrossRef]

5. Correia, L., and C. Flores. 2017. The Role of Input Factors in the Lexical Development of European Portuguese as a Heritage Language in Portuguese-German Bilingual Speakers. Languages 2: 30. [CrossRef]

6. Wood, C.L., K.N. Bustamante, L.M. Fitton, D.M. Brown, and Y. Petscher. 2017. Rapid Automatic Naming Performance of Young Spanish-English Speaking Children. Languages 2: 13. [CrossRef]

7. Rodriguez, E., K. Bustamante, C. Wood, and G. Sunderman. 2017. A Comparison of the Grammatical Production of Child Heritage Speakers of Spanish across Language and Grade: Kindergarten and Grade 1. Languages 2: 27. [CrossRef]

8. Morales-Reyes, A., and B. Arechabaleta-Regulez. 2017. Are Lions Green?: Child L2 Learners' Interpretation of English Generics and Definite Determiners. Languages 2: 22. [CrossRef]

9. Parma, A. 2017. Cross-Linguistic Transfer of Object Clitic Structure: A Case of L3 Brazilian Portuguese. Languages 2: 14. [CrossRef]

(C) 2017 by the authors. Licensee MDPI, Basel, Switzerland. This article is an open access article distributed under the terms and conditions of the Creative Commons Attribution (CC BY) license (http://creativecommons.org/licenses/by/4.0/). 